\title{
The disgust scale-R: A valid and reliable index to investigate separate disgust domains?
}

Citation for published version (APA):

van Overveld, M., de Jong, P. J., Peters, M. L., \& Schouten, E. (2011). The disgust scale-R: A valid and reliable index to investigate separate disgust domains? Personality and Individual Differences, 51(3), 325330. https://doi.org/10.1016/j.paid.2011.03.023

Document status and date:

Published: 01/01/2011

DOI:

10.1016/j.paid.2011.03.023

Document Version:

Publisher's PDF, also known as Version of record

Document license:

Taverne

Please check the document version of this publication:

- A submitted manuscript is the version of the article upon submission and before peer-review. There can be important differences between the submitted version and the official published version of record.

People interested in the research are advised to contact the author for the final version of the publication, or visit the DOI to the publisher's website.

- The final author version and the galley proof are versions of the publication after peer review.

- The final published version features the final layout of the paper including the volume, issue and page numbers.

Link to publication

\footnotetext{
General rights rights.

- You may freely distribute the URL identifying the publication in the public portal. please follow below link for the End User Agreement:

www.umlib.nl/taverne-license

Take down policy

If you believe that this document breaches copyright please contact us at:

repository@maastrichtuniversity.nl

providing details and we will investigate your claim.
}

Copyright and moral rights for the publications made accessible in the public portal are retained by the authors and/or other copyright owners and it is a condition of accessing publications that users recognise and abide by the legal requirements associated with these

- Users may download and print one copy of any publication from the public portal for the purpose of private study or research.

- You may not further distribute the material or use it for any profit-making activity or commercial gain

If the publication is distributed under the terms of Article $25 \mathrm{fa}$ of the Dutch Copyright Act, indicated by the "Taverne" license above, 


\title{
The Disgust Scale-R: A valid and reliable index to investigate separate disgust domains?
}

\author{
Mark van Overveld ${ }^{\mathrm{a}, *}$, Peter J. de Jong ${ }^{\mathrm{b}}$, Madelon L. Peters ${ }^{\mathrm{c}}$, Erik Schouten ${ }^{\mathrm{c}}$ \\ a Marketing Management, Erasmus University Rotterdam, P.O. Box 1738, 3000 DR Rotterdam, The Netherlands \\ ${ }^{\mathrm{b}}$ Department of Clinical Psychology, University of Groningen, Grote Kruisstraat 2/1, 9712 TS Groningen, The Netherlands

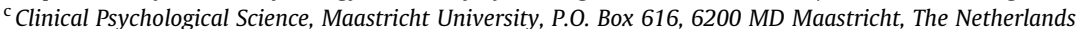

\section{A R T I C L E I N F O}

\section{Article history:}

Received 7 October 2010

Received in revised form 7 February 2011

Accepted 16 March 2011

Available online 6 May 2011

\section{Keywords:}

Disgust Scale

Trait disgust

Disgust propensity

Reliability

Validity

Psychometric evaluation

\begin{abstract}
A B S T R A C T
The Disgust Scale (DS; Haidt, McCauley, \& Rozin, 1994) is the most widely used instrument for assessing disgust propensity (i.e., individual tendency to experience disgust). Yet, psychometric evaluations of the DS are scarce while the literature shows that the reliability of its subscales are unacceptably low. Recently, it was suggested to reduce the number of subscales (Olatunji, Sawchuk, de Jong, \& Lohr, 2007a). This study is a first exploration of this reduced three-factor solution in an independent sample. In study I, we examined whether a three-factor solution improves psychometric properties of the DS. Students from Maastricht University $(N=535)$ and the University of Groningen $(N=432)$ completed the DS. In study II, the DS was revised by dropping redundant items and revising its scoring format. The DS-R was administered to students from the University of Groningen $(N=472)$ and Ghent University $(N=41)$ to study its psychometric properties. The revisions improved the psychometric features of the DS, and showed that the DS-R is a valid and reliable index to establish core disgust, animal-reminder disgust, and contamination.
\end{abstract}

Crown Copyright $\odot 2011$ Published by Elsevier Ltd. All rights reserved.

\section{Introduction}

Disgust propensity is defined as the individual tendency to experience disgust. Research showed that enhanced disgust propensity is associated with various psychopathological conditions (Olatunji \& Sawchuk, 2005). It has been argued that high levels of disgust propensity enlarge the probability of specific stimuli to acquire a disgust-evoking status (van Overveld, de Jong, \& Peters, 2010). Hence, disgust propensity is assumed to be particularly important to the etiology of psychopathological conditions in which disgust is somehow involved. Accordingly, previous research showed that enhanced disgust propensity is involved in spider phobia (Matchett \& Davey, 1991), blood phobia (de Jong \& Merckelbach, 1998), obsessive compulsive disorder (Mancini, Gragnani, \& D’Olimpio, 2001; Olatunji, Williams, Lohr, \& Sawchuk, 2005), and sexual dysfunctions (de Jong, van Overveld, WeijmarSchultz, Peters, \& Buwalda, 2009).

Although several disgust types have been identified in the literature, only two are well-examined: core and animal-reminder disgust (AR; Rozin, Haidt, \& McCauley, 2000). Core disgust involves disgust at the prospect of oral incorporation of disgusting stimuli (e.g., rotting foods), whereas AR-disgust involves an aversion

\footnotetext{
* Corresponding author. Tel.: +31 10 4081970; fax: +31 104089572.

E-mail address: MOverveld@RSM.nl (M. van Overveld).
}

towards stimuli that remind humans of their animal nature (Rozin \& Fallon, 1987). These two disgust types can be empirically established and may be related differentially to psychopathology (de Jong \& Merckelbach, 1998).

However, current indices generally do not measure these latent concepts (core/AR-disgust) but rather measure disgust propensity for specific disgust stimuli. The Disgust Scale (DS; Haidt et al., 1994 ) is the most widely used instrument on disgust propensity. Yet, despite its widespread use, psychometric evaluations are scarce. This is particularly troublesome, as studies consistently report that although internal consistency for the total index is good $(\alpha=.84$; Haidt et al., 1994; .74; Olatunji, Smits, Connolly, Willems, \& Lohr, 2007b), its subscales demonstrate low to moderate reliability ( $\alpha$ 's = .34-.64; Haidt et al., 1994; .40-.68; Olatunji et al., 2005). Further, the DS measures disgust for specific elicitors but not explicitly core or AR-disgust. Thus, internal consistency may be improved by creating subscales covering larger disgust domains (core/AR).

A first exploration provided preliminary support. Earlier work investigated correlations between the DS and blood phobia symptoms (Olatunji, Sawchuk, de Jong, \& Lohr, 2006). The DS-items were reallocated in subscales measuring core and AR-disgust. Structural equation modeling showed domain-specific correlations between these subscales and blood phobia symptoms. Moreover, the two-factor model fitted the data well (Olatunji et al., 2006). 
Recently, Olatunji and Sawchuk et al. (2007a) examined the DS and suggested several adjustments. First, seven items were removed due to redundancy. Second, confirmatory factor analyses demonstrated that, compared to a one- or two-factor model, a three-factor solution (Core, AR, Contamination) had superior fit. Contamination can be defined as an individual's fear of contagion with disgusting stimuli. Contamination potency, the ability to contaminate a non-disgusting object with disgust-inducing qualities, is an important feature of disgust stimuli, particularly for psychopathology (e.g., de Jong \& Muris, 2002).

The aim of the present studies was to determine whether psychometric properties of the DS would improve following a revision in accordance with earlier recommendations (Olatunji \& Sawchuk et al., 2007a; Olatunji et al., 2007c). In the first study, we investigated whether assigning DS-items into the three proposed subscales in line with the three-factor model (Core/AR/Contamination) fitted the data better than the original or a two-factor solution (Core/AR). In the second study, the DS was fully revised in accordance with Olatunji's suggestions, and its psychometric properties were explored using confirmatory factor analyses. Content validity was examined by means of correlations with other disgust propensity indices.

\section{Study I}

\subsection{Methods}

\subsubsection{Participants}

Students from the schools of Psychology, Health Sciences, and Medicine at Maastricht University $(N=535 ; 443$ women $)$ and the University of Groningen ( $N=432 ; 316$ women) were recruited. Their mean age was 20.4 years $(S D=2.4$; range: $17-39$ years).

\subsection{Materials}

\subsubsection{Disgust Scale (DS; Haidt et al., 1994)}

The DS measures individuals' disgust propensity across eight domains: Animals, Bodily Products, Body-Envelope Violations, Death, Food, Hygiene, Sex, and Sympathetic Magic. On the first part, participants indicate whether sixteen statements apply to them on a dichotomous scale $(0=$ 'no', $1=$ 'yes'). On the second part, participants rate) how disgusted they are when confronted with several stimuli on a three-points Likert-scale $(0=$ 'not disgusting at all', .5 = 'slightly disgusting', 1 = 'very disgusting'). A total score (range: $0-32$ ) and eight subscales (range: $0-4$ ) can be calculated. Recent work suggested to shorten the DS to 25 items with three subscales. Thus, we recalculated the total score of the original 32-item DS to form the 25-item DS-A (DS-Adapted) with subscales Core, AR, and Contamination.

\subsection{Procedure}

For three consecutive years, students from Maastricht University participated in a questionnaire study. During the third administration, a similar study was performed at the University of Groningen. In Maastricht, groups (max. 25 participants per group) completed the DS in a conference room. In Groningen, participants completed the DS in a lecture theatre setting. All completed the Dutch version of the DS. Its psychometric features are comparable to the English version (e.g., Olatunji et al., 2009). Participants were recruited via advertisements in university papers and posters throughout the university buildings. On behalf of another study (van Overveld, de Jong, Peters, Cavanagh, \& Davey, 2006), several questionnaires on emotions, trait disgust and psychopathology were administered. Participants were informed that they could win 50 euro through a lottery.

\subsection{Data analysis}

The data were pooled into one sample. Regression analyses computed missing values using the Statistical Package for Social Sciences (SPSS; version 12.0.1). Overall, less than $1 \%$ missing data were observed. First, descriptives of all questionnaires were calculated for the entire research population $(N=967)$. Hereto, the 25 DS-A items were used to comprise the subscales from the twoand three-subscale solutions proposed by Olatunji et al. (2007c). Additionally, a version of the DS was calculated where the 25 DS-A items were assigned to their original subscales. So, compared to the original 32-item version, the Sex-subscale was deleted and subscales Food, Body and Envelope Violations contained one item less.

Second, confirmatory factor analyses (CFA) determined whether the three-factor model fitted significantly better than a one-, twoor seven factor model, and whether the DS-A models demonstrated good model fit. In accordance with Olatunji et al. (2007c), in the two-factor model, the Core-disgust factor comprised the items from subscales Food, Animal, Body Products, Hygien, and Magic, the AR-disgust factor consisted of items from Envelope and Death. In the three-factor model, Contamination comprised five items $(9$, $11,24,28,29$ of the Dutch DS) which were omitted from the Core Disgust factor. Polychoric correlation matrices and asymptotic covariance matrices were obtained by PRELIS. Using LISREL 8.54 (Jöreskog \& Sörbom, 2002), confirmatory factor analyses were performed with the Weighted Least-Squares estimation due to the discrete scoring format of the first part of the DS-A. Latent variables were free to correlate. Secondary loadings of items were not permitted.

\section{Results}

\subsection{Descriptives}

Table 1 summarizes the descriptive statistics of all questionnaires. Internal consistency was acceptable for the DS-A total score $(\alpha=.70)$, but low for all subscales.

Table 1

Summary of means, standard deviations and reliability coefficients for all disgust indices.

\begin{tabular}{lrrll}
\hline & Mean & \multicolumn{1}{l}{ SD } & Range & Cronbach's alpha \\
\hline DS-A total & 17.57 & 4.77 & $3-32$ & .70 \\
DS-A-Ani & 3.72 & 1.26 & $0-4$ & .30 \\
DS-A-Food & 2.24 & 1.13 & $0-4$ & .14 \\
DS-A-Body & 2.15 & 1.03 & $0-4$ & .31 \\
DS-A-Hyg & 2.36 & 1.08 & $0-4$ & .21 \\
DS-A-Env & 2.75 & .91 & $0-4$ & .12 \\
DS-A-Death & 2.59 & 1.53 & $0-4$ & .43 \\
DS-A-Magic & 1.76 & 1.10 & $0-4$ & .28 \\
DS-A two subscales & & & & \\
DS-A-Core & 11.56 & 3.40 & $1-22$ & .61 \\
DS-A-AR & 6.01 & 2.18 & $0-11$ & .52 \\
DS-A three subscales & & & & \\
DS-A-Core & 10.12 & 2.90 & $0-18$ & .59 \\
DS-A-AR & 6.01 & 2.18 & $0-11$ & .52 \\
DS-A-Cont & 1.44 & 1.17 & $0-7$ & .27 \\
\hline
\end{tabular}

SD, Standard Deviation; DES, Disgust Emotion Scale; DQ, Disgust Questionnaire; DSA, Disgust Scale-Adapted; Ani, Animals; Body, Body Products; Hyg, Hygiene; Env, Body-Envelope Violations; Magic, Sympathetic magic; Cont, Contamination. 
Table 2

Goodness of fit indices for all DS-R models.

\begin{tabular}{lllllllll}
\hline & $\chi^{2}$ & d.f. & $\begin{array}{l}\chi^{2} / \\
\text { d.f. }\end{array}$ & CFI & TLI & RMSEA & ECVI & SRMR \\
\hline One factor & 1796.14 & 275 & 6.53 & .66 & .63 & .07 & 1.96 & .20 \\
Two factors & 1788.34 & 274 & 6.53 & .66 & .63 & .08 & 1.95 & .20 \\
Three factors & 1742.68 & 272 & 6.41 & .67 & .64 & .07 & 1.92 & .20 \\
Seven factors & 1663.28 & 254 & 6.55 & .68 & .62 & .08 & 1.87 & .21 \\
Valid $N$ & & & & & & & 966 & \\
\hline
\end{tabular}

Note: CFI, Comparative Fit Index; TLI, Tucker-Lewis Index; RMSEA, Root Mean Square Error of Approximation; ECVI, Expected Cross-Validation Index; SRMR, Standardized Root Mean Square Residual.

\subsection{Confirmatory factor analysis}

Model fit was examined using absolute and incremental fit indices. The chi-square ratio $\left(\chi^{2} / \mathrm{df}\right)$ is an absolute fit index. Generally, a ratio below 3 indicates reasonable fit. Here, a poor fit was observed for all models.

For the incremental fit indices, model fit was examined using cut-off criteria by $\mathrm{Hu}$ and Bentler (1999): Comparative Fit Index $(\mathrm{CFI}) \geqslant .95$, Tucker-Lewis Index $(\mathrm{TLI}) \geqslant .95$, Root Mean Square Error of Approximation (RMSEA) $\leqslant .06$. Additionally, the Standardized Root Mean Square Residual (SRMR) was used to examine model fit (SRMR <.9 indicates good fit). Table 2 shows that all models displayed poor model fit.

\section{Discussion}

Study I showed that all factor models demonstrated poor fit. In line with previous research (Olatunji et al. (2007c)), the seven-factor model displayed poor psychometric characteristics. Internal consistency was only acceptable for the total score. Yet, reallocating the items in fewer factors did enhance internal consistency, although it should be noted that calculations of reliability depend on the number of items, where a higher number of items in a subscale automatically increases alpha-values. Additionally, CFA demonstrated poor fit for all models.

An explanation for the poor fit of all models may be the troublesome scoring format of the DS, but also the focus of its questions. Present disgust models value both the distinction between Core and AR-domains and contamination potency as important qualities of disgust stimuli (e.g., Rozin, Haidt, \& McCauley, 2009). In the context of psychopathology, disgust propensity and contamination sensitivity have been differentially associated with several clinical complaints (e.g., Olatunji, Sawchuk, Lohr, \& de Jong, 2004) which emphasizes the theoretical importance of obtaining an index that adequately distinguishes between disgust propensity for Core/ AR-domains and contamination potency.

Therefore, in study II, we revised the DS following the recommendations by Olatunji and Sawchuk et al. (2007a) and examined the validity of a three-factor model (Core, AR, Contamination). First, several items were deleted. Second, two filler items were included. Third, a five-point Likert scale was implemented for all questions. This study represents the first test of the psychometric properties of the DS-R when consistently revised in accordance with all recommendations. Because the results of study I did not convincingly favour a specific solution, one-, two- and three-factor distributions were explored in study II. To examine convergent validity, associations were explored with two disgust propensity indices (DPSS-R-propensity, DES-total). Secondly, we investigated whether domain-specific scales of the DES were differentially associated with the Core and AR-scales of the DS-R.

\section{Study II}

\subsection{Participants}

Data from three questionnaire studies at the University of Groningen and Ghent University were pooled in one dataset $(N=472)$. Given the predominance of female students at these schools, combined with inclusion criteria of two studies (only female participants), women were overrepresented (81.3\%; $n=378$; men: $18.7 \% ; n=87$ ). The mean age was 18.52 years $(S D=1.13$; range: 17-25). More precisely, the first dataset contained 63 women with a mean age of 18.51 years $(S D=1.11 ; 17-25)$, the second dataset 41 women with a mean age of $18.53(S D=1.18 ; 17-22)$, and the third dataset had 368 participants ( 87 men, 274 women, 7 gender not disclosed). In the third dataset, age was not measured. Since this set consisted of undergraduates, mean age is most likely approximately 20 years.

\subsection{Instruments}

In addition to the DS- $R$, the following indices were administered:

\subsubsection{Disgust emotion scale (DES; Walls E' Kleinknecht, 1996)}

This 30-item questionnaire measures disgust propensity for five types of stimuli: Animals (DES-Ani), Rotting Foods (DES-Food), Odor (DES-Odor), Mutilation (DES-Mut), and Injections (DES-Inj). The first three may measure core-disgust, the latter two AR-disgust. On a scale from 0 ('no disgust at all') to 4 ('extreme disgust'), participants rate how much disgust they would experience when for specific objects. Both a total score and five subscales can be calculated that are internally consistent (all $\alpha$ 's between .73 and .87; Sawchuk, Lohr, Westendorf, Meunier, \& Tolin, 2002).

\subsubsection{Disgust propensity and sensitivity Scale-Revised (DPSS-R; van} Overveld et al., 2006)

The DPSS-R measures disgust propensity (i.e. tendency to experience disgust) and disgust sensitivity (i.e., tendency to evaluate experiencing disgust negatively). The recently revised version was used (Fergus \& Valentiner, 2009), where participants rate 12 items on a scale from 1 (= 'never') to 5 (= 'always'). The DPSS-R is reliable and valid (Fergus \& Valentiner, 2009).

\subsection{Procedure}

Participants received the questionnaires during a yearly screening in undergraduates at the University of Groningen or before participating in an experiment at Ghent University. They completed Dutch versions of the DS-R, DES, DPSS-R, and a package of questionnaires on several topics on behalf of other studies. Participants received course credit for their participation.

\subsection{Data analyses}

The data from three datasets were pooled into one sample. Regression analyses were used to compute missing values with the Statistical Package for Social Sciences (SPSS 12.0.1.). Less than $1 \%$ missing values were observed. Next, CFA examined whether the three-factor solution was confirmed and displayed better psychometric features than two factors or a null-model (one-factor). As the DS-R contained a five-point Likert format, Maximum Likelihood was now considered the most appropriate estimation method. Polychoric correlation matrices were obtained by PRELIS, while the CFA was performed in LISREL 8.54 (Jöreskog \& Sörbom, 2002). Latent variables were allowed to correlate while secondary 
Table 3

Lambda factor loading of CFA for the DS-R.

\begin{tabular}{rrrl}
\hline DS-R item & Core & AR & Contamination \\
\hline 13 & -.82 & & \\
8 & -.75 & & \\
27 & -.66 & & \\
15 & -.65 & & \\
11 & -.61 & & \\
3 & -.59 & & \\
17 & -.54 & & \\
22 & -.53 & & \\
25 & -.52 & & \\
20 & -.49 & & \\
1 & -.40 & .72 & \\
6 & .29 & .72 & \\
2 & & .71 & \\
24 & & .70 & \\
19 & & .68 & \\
7 & & .65 & .34 \\
21 & & .64 & \\
14 & & -.50 & \\
5 & & & .56 \\
10 & & & \\
23 & & & \\
9 & & & \\
26 & & & \\
4 & & & \\
18 & & & \\
\hline
\end{tabular}

loadings of items were not permitted. For the three factor model: Items $1,3,6,8,11,13,15,17,20,22,25,27$ were used for Core Disgust, items 2, 5, 7, 10,14, 19, 21, 24 for AR-disgust, and items 4, 9, 18, 23, 26 for Contamination. For the two-factor model, Core and Contamination formed one factor. In the one-factor model, all items were regarded as reflecting one factor. Finally, bivariate correlations were calculated in the total sample to examine convergent validity. Table 3 presents the factor loadings of the DS-R.

\subsection{Descriptives}

In Table 4, means, standard deviations and internal consistencies of the DS-R solutions are presented. Internal consistency was good for the total score $(\alpha=.87)$ and subscales Core and AR (both $\alpha$ 's .78), while low for Contamination $(\alpha=.54)$.

\subsection{Confirmatory factor analysis}

Absolute and incremental fit indices were used to examine model fit. Table 5 shows that for the absolute fit index, the chisquare ratio $\left(\chi^{2} / \mathrm{df}\right)$, all models demonstrated reasonable (one-factor) to acceptable fit (two- and three-factor models). For the incre-

Table 4

Summary of means, standard deviations and internal consistencies of the two and three-subscales DS.

\begin{tabular}{lllll}
\hline & Mean & SD & Range & Cronbach's alpha \\
\hline DS-R-total & 50.45 & 14.14 & $8-87$ & .87 \\
Two factors & & & & \\
DS-R-Core & 30.69 & 9.55 & $5-58$ & .81 \\
DS-R-AR & 18.73 & 6.04 & $0-32$ & .78 \\
Three factors & & & & \\
DS-R-Core & 26.16 & 7.69 & $4-46$ & .78 \\
DS-R-AR & 18.73 & 6.04 & $0-32$ & .78 \\
DS-R-Cont & 5.56 & 3.15 & $0-17$ & .54 \\
\hline
\end{tabular}

SD, Standard Deviation; DS-R, Disgust Scale-Revised; Core, Core disgust; AR, Animal-Reminder disgust; Cont, Contamination.
Table 5

Goodness of fit indices for DS-R.

\begin{tabular}{lllllllll}
\hline & $\chi^{2}$ & d.f. & $\chi^{2} /$ d.f. & CFI & TLI & RMSEA & ECVI & SRMR \\
\hline One factor & 881.46 & 275 & 3.21 & .92 & .91 & .08 & 2.49 & .07 \\
Two factors & 607.31 & 274 & 2.27 & .91 & .90 & .08 & 3.34 & .08 \\
Three factors & 708.29 & 272 & 2.60 & .94 & .94 & .06 & 1.88 & .06 \\
Valid $N$ & & & & & & & & 472 \\
\hline
\end{tabular}

Note: CFI, Comparative Fit Index; TLI, Tucker-Lewis Index; RMSEA, Root Mean Square Error of Approximation; ECVI, Expected Cross-Validation Index; and SRMR, Standardized Root Mean Square Residual.

mental fit indices, model fit only approached acceptable parameters for the three-factor model.

To compare the nested models, the chi-squares difference test was used. Compared to the one-factor model, a two-factor model fitted the data significantly better $\left(\chi_{\text {diff }}^{2}(1)=91.10 ; p<.01\right)$. The differences were also significant when comparing the three-factor model to the one-factor model $\left(\chi_{\text {diff }}^{2}(3)=173.20 ; p<.01\right)$ or the two-factor model $\left(\chi_{\text {diff }}^{2}(2)=82.12 ; p<.01\right)$. Thus, adding a Contamination-factor to the model appears a significant improvement. Additionally, to assess the fit of competing models, the Expected Cross-Validation Index (ECVI) was used. The ECVI was lowest for the three-factor model, so, this model proved superior to a one and two-factor solution. Finally, although SRMR demonstrated good fit for all three models, the three-factor model fitted best.

\subsection{Content validity}

Table 6 shows that although the three subscales of the DS-R were moderately to highly intercorrelated, there is enough unexplained variance to conclude that the three scales measure different concepts. All DS-R scales correlated moderately with disgust propensity (DPSS-RP) and disgust sensitivity (DPSS-RS), and moderately to high with the DES. Supporting the validity of the DS, DS-R-Core correlated highest with DES-subscales Food, Odor, and Animals, while DS-R-AR correlated highest with Mutilation. In other words, differential correlations were observed for the domain-specific DS-R subscales (Core/AR).

\section{Discussion}

The three factor structure displayed a superior fit compared to both one- and two-factor models. Thus, the DS-R measures three factors convincingly: Core-disgust, AR-disgust, and Contamination.

Table 6

Correlations between DS-R and trait disgust (DPSS-R, DES).

\begin{tabular}{lllll}
\hline Disgust indices & DS-R total & Core & AR & Cont \\
\hline DS-R Core & .93 & & & \\
DS-R AR & .86 & .68 & & \\
DS-R Cont & .57 & .42 & .29 & \\
DPSS-RP & .49 & .49 & .43 & .18 \\
DPSS-RS & .40 & .38 & .33 & .26 \\
DES-total & .75 & .72 & .62 & .40 \\
DES-Food & .54 & .58 & .37 & .32 \\
DES-Inj & .43 & .35 & .40 & .29 \\
DES-Odor & .64 & .67 & .44 & .39 \\
DES-Anim & .58 & .58 & .44 & .34 \\
DES-Mut & .63 & .56 & .66 & .18 \\
Valid $N$ & & & & 472 \\
\hline
\end{tabular}

Abbreviations: DS-R, Disgust Scale - Revised; AR, Animal-Reminder Disgust; Cont Contamination; DPSS-RP, Disgust Propensity and Sensitivity Scale-Revised Propensity; DPSS-RS, Disgust Propensity and Sensitivity Scale-Revised Sensitivity; DES, Disgust Emotion Scale; Inj, Injections; Anim, Small Animals; and Mut, Mutilation. All correlations significant at $p<.01$. 
Although the Contamination-subscale appears to measure a unique aspect of disgust, its internal consistency remained low, so future revisions of this subscale seem warranted. Nevertheless, CFA suggests that including contamination potency appears a valuable addition to the model, and its clinical relevance is potentially important (e.g., in explaining avoidance behavior in OCD).

Further, the DS-R subscales correlated meaningfully with established disgust propensity indices. More noteworthy, the DS-R displayed stronger associations than previous reports (e.g., $r=.37$ between DS and DPSS-R Propensity, $r=.29$ between DS and DPSSR Sensitivity; van Overveld et al., 2006). Thus, revising the scoring format critically improved psychometric properties of the DS.

\section{General discussion}

Prior research showed that the psychometric aspects of the DS were not satisfactory. The present study is a first investigation of a version that was consistently revised in accordance with earlier suggestions (i.e., Olatunji et al. (2007c)) and which is proposed to measure core disgust, AR-disgust and contamination. Factor analyses revealed that three factors can be readily distinguished in the original DS (i.e., the 25 retained items from Olatunji et al. (2007c)) and the DS-R. In both studies, the three-factor model fitted better than a one- or a two-factor model. Thus, contamination potency (i.e., contamination-subscale) appears an essential component of disgust stimuli (Olatunji et al., 2005; Olatunji and Sawchuk et al. (2007a)).

Further, these findings replicated earlier work (Olatunji et al., 2005) by showing that the DS can differentiate between core and AR-disgust. DS-R Core was associated most strongly with core disgust-related DES-subscales Odor, Food, and Animals, whereas DS-R AR was most strongly associated with AR-related DES-Mutilation.

These indications that the DS-R measures distinct disgust types are theoretically and clinically important. Theoretically, since recent disgust models propose a two-stage model (Rozin et al., 2009). Here, core disgust is regarded as the most primal form of disgust from which all other disgust types evolved (e.g., AR-disgust). If these disgust types indeed present distinct disgust categories, then propensities for these disgust types may be differentially associated with behavioral tendencies.

Previous research already indicated that these disgust types could be differentially involved in psychopathology (e.g., core disgust in spider phobia, AR-disgust in blood phobia; de Jong \& Merckelbach, 1998). Thus, from a clinical perspective, it would be pivotal to have a reliable and valid index available to examine disgust propensities. Thus far, no instrument reliably differentiates between individuals' propensity for core versus AR-disgust stimuli. The DS-R is the first reliable solution to assess both types of disgust propensity separately. Additionally, current analyses confirm a third subscale, Contamination, which reflects the contamination potency of disgust stimuli. Contamination potency may be a likely candidate for explaining avoidance behavior in obsessive-compulsive behavior.

\subsection{Future directions}

Several future modifications may further improve the psychometric properties of the DS-R. First, the Contamination-subscale was not internally consistent and correlations with other disgust indices were low. Since calculations of reliability depend heavily on the number of items, the low reliability of this subscale might simply reflect the low number of items of this scale. The low reliability might also have suppressed correlations with other indices of disgust. It would be interesting in future research to test whether increasing the number of items in this subscale might be helpful to enhance its psychometric features.
Second, although the scoring format is similar for all items, the DS-R is still divided into two parts with different questions. Most items on the first part significantly correlated low to moderate (all $r$ 's $<.50$ ) with domain counterparts on the second part. Only for Contamination, correlations were consistently low ( $r$ 's $<.27$ ). Questions of the second part directly ask for anticipated disgust levels when confronted with specific stimuli. Items of the first part only indirectly reflect individuals' disgust propensity by asking individuals' anticipated tendency to avoid certain (disgust-eliciting) stimuli. Although both anticipated avoidance tendencies and anticipated feelings of disgust may be relevant components of disgust propensity, they could be differentially involved in guiding people's behavior related to potentially disgusting stimuli. If so, such differential involvement could be related to various aspects of psychopathology. For example, anticipated avoidance tendencies may be related to the occurrence of rituals and avoidance of specific actions (e.g., entering places with spiders in spider phobia), while anticipated feelings may induce stronger compensation behavior (e.g., washing in OCD-patients). Future research should investigate potential predictive validity of both parts of the DS.

\subsection{Study limitations}

Several comments apply to the present study. First, we investigated construct validity but not any other validity types (e.g., predictive validity). It should be investigated whether higher scores on DS-R-subscales (Core, AR, Contamination) can predict behavioral avoidance in behavioral experiments (e.g., van Overveld et al., 2010). This is important given the assumption that elevated levels of a propensity for specific disgust types may be related to clinical avoidance patterns for various stimuli (e.g., spiders, medical procedures, physical contact with people).

At this stage, the three-factor DS-R with a uniform scoring format, appears a significant improvement from a psychometric stance. Yet, the contamination-subscale requires further revision. Nevertheless, for both theoretical and applied research on the differential involvements of core and AR-disgust propensities, the DS$\mathrm{R}$ appears a suitable index.

\section{Acknowledgements}

For their efforts with respect to data collection, the present authors extend their gratitude to Joëlle Janssen, Judith Deutz, Leon ter Hart, Janna Janssen, Julia Degner, and Julia Vogt.

\section{References}

de Jong, P., \& Merckelbach, H. (1998). Blood-injection-injury phobia and fear of spiders: Domain specific individual differences in disgust sensitivity. Personality and Individual Differences, 24, 153-158.

de Jong, P., \& Muris, P. (2002). Spider phobia: interaction of disgust and perceived likelihood of involuntary physical contact. Journal of Anxiety Disorders, 16, 51-65.

de Jong, P. J., van Overveld, M., Weijmar-Schultz, W., Peters, M. L., \& Buwalda, F. M. (2009). Disgust and contamination sensitivity in vaginismus and dyspareunia. Archives of Sexual Behavior, 38, 244-252.

Fergus, T. A., \& Valentiner, D. P. (2009). The Disgust Propensity and Sensitivity Scale-Revised: An examination of a reduced-item version. Journal of Anxiety Disorders, 23, 703-710.

Haidt, J., McCauley, C., \& Rozin, P. (1994). Individual differences in sensitivity to disgust: a scale sampling seven domains of disgust elicitors. Personality and Individual Differences, 16, 701-713.

Hu, L.-T., \& Bentler, P. M. (1999). Cut-off criteria for fit indexes in covariance structure analysis: Conventional criteria versus new alternatives. Structural Equation Modeling, 6, 1-55.

Jöreskog, K. G., \& Sörbom, D. (2002). LISREL 8.54. Chicago: Scientific Software International, Inc.

Mancini, F., Gragnani, A., \& D'Olimpio, F. (2001). The connection between disgust and obsessions and compulsions in a non-clinical sample. Personality and Individual Differences, 31, 1173-1180. 
330

M. van Overveld et al./Personality and Individual Differences 51 (2011) 325-330

Matchett, G., \& Davey, G. C. L. (1991). A test of a disease-avoidance model of animal phobias. Behaviour Research and Therapy, 29, 333-335.

Olatunji, B. O., Moretz, M. W., McKay, D., Bjorklund, F., de Jong, P. J., Haidt, J., et al. (2009). Confirming the three-factor structure of the Disgust Scale-Revised in eight countries. Journal of Cross-Cultural Psychology, 40, 234-255.

Olatunji, B. O., \& Sawchuk, C. N. (2005). Disgust: characteristic features, social manifestations, and clinical implications. Journal of Social and Clinical Psychology, 24, 932-962.

Olatunji, B. O., Sawchuk, C. N., de Jong, P. J., \& Lohr, J. M. (2006). The structural relation between disgust sensitivity and blood-injection-injury fears: A crosscultural comparison of US and Dutch data. Journal of Behavior Therapy and Experimental Psychiatry, 37, 16-29.

Olatunji, B. O., Sawchuk, C. N., de Jong, P. J., \& Lohr, J. M. (2007a). Disgust sensitivity in anxiety disorder symptoms. Journal of Psychopathology and Behavioral Assessment, 19, 281-297.

Olatunji, B. O., Sawchuk, C. N., Lohr, J. M., \& de Jong, P. J. (2004). Disgust domains in the prediction of contamination fear. Behaviour Research and Therapy, 42, 93-104.

Olatunji, B. O., Sits, J. A., Connolly, K. M., Willems, J., \& Lohr, J. M. (2007b). Examination of the rate of decline in fear and disgust during exposure to threat-relevant stimuli in blood-injection-injury phobia. Journal of Anxiety Disorders, 21, 445-455.

Olatunji, B. O., Williams, N. L., Lohr, J. M., \& Sawchuk, C. N. (2005). The structure of disgust: Domain specificity in relation to contamination ideation and excessive washing. Behaviour Research and Therapy, 43, 1069-1086.
Olatunji, B. O., Williams, N. L., Tolin, D. F., Sawchuk, C. N., Abramowitz, J. S., Lohr, J. M., et al. (2007c). The disgust scale: Item analysis, factor structure, and suggestions for refinement. Psychological Assessment, 19, 281-297.

Rozin, P., \& Gallon, A. E. (1987). A perspective on disgust. Psychological Review, 94, 23-41.

Rozin, P., Haidt, J., \& McCauley, C. R. (2000). Disgust. In Lewis, M. \& Haviland Jones, J. M. (Ed.), Handbook of Emotions, and edition (637-652). New York: Guilford Press.

Rozin, P., Haidt, J., \& McCauley, C. R. (2009). Disgust: The body and soul emotion in the 21 st century. In B. O. Olatunji \& D. McKay (Eds.), Disgust and its disorders: Theory, assessment, and treatment implications. Washington DC: American Psychological Association.

Sawchuk, C. N., Lohr, J. M., Westendorf, D. H., Meunier, S. A., \& Tolin, D. F. (2002). Emotional responding to fearful and disgusting stimuli in specific phobia. Behaviour Research and Therapy, 40, 1031-1046.

van Overveld, M., de Jong, P. J., \& Peters, M. L. (2010). The disgust propensity and sensitivity scale-revised: Its predictive value for avoidance behavior. Personality and Individual Differences, 49, 706-711.

van Overveld, W. J. M., de Jong, P. J., Peters, M. L., Cavanagh, K., \& Davey, G. C. L. (2006). Disgust propensity and disgust sensitivity: Separate constructs that are differentially related to specific fears. Personality and Individual Differences, 41, 1241-1252.

Walls, M. M., \& Kleinknecht, R. A. (1996). Disgust factors as predictors of bloodinjury fear and fainting. San Jose, CA: Paper presented at the annual meeting of the Western Psychological Association. 